\title{
FORMAÇÃO DE EDUCADORES A DISTÂNCIA NA PÓS-GRADUAÇÃO: POTENCIALIDADES PARA O DESENVOLVIMENTO DA INVESTIGAÇÃO E PRODUÇÃO DE CONHECIMENTO
}

\author{
Maria ElizABETh Bianconcini De AlmeidA*
}

RESUMO: O objetivo deste trabalho é oferecer subsídios para a formação a distância de educadores em cursos de pós-graduação stricto sensu, comprometidos com a investigação, os avanços da produção científica e a publicação de seus resultados. O trabalho está estruturado em três partes: visão geral das políticas, regulamentação e estrutura da educação a distância no ensino superior brasileiro; princípios da interação, reflexão, investigação, colaboração e construção do conhecimento; contribuições para a realização de cursos de pós-graduação a distância.

Palavras-chave: Educação a distância. Pós-graduação. Pesquisa. Construção de conhecimentos. Ambiente virtual de aprendizagem.

\section{DISTANCE EDUCATORS TRAINING IN POST-GRADUATE: DEVELOPMENT OF RESEARCH AND PRODUCTION OF KNOWLEDGE POTENTIAL}

ABSTRACT: The purpose of this work is to offer evidence for distance teacher training programs in postgraduate programs based in the commitment with the investigation, the advances of scientific writings and the publication of results. This work is structured in three parts, mainly: general view of policies, regulation and structuring of distance learning in Brazilian higher education; principles of interaction, reflection, investigation, collaboration and development of knowledge; indications of contributions for the development of distance education postgraduate programs.

Key words: Distance education. Post-graduate. Research. Knowledge development. Virtual learning environment.

* Doutora em Educação e professora do Departamento de Formação Docente, Gestão e Tecnologias da Pontifícia Universidade Católica de São Paulo (PUC-SP). E-mail: bethalmeida@pucsp.br 
FORMATION DES ÉDUCATEURS À DISTANCE EN TROISIÈME CYCLE: POTENTIELS POUR LE DEVELOPPEMENT DE LA RECHERCHE ET DE LA PRODUCTION DE CONNAISSANCES

RÉSUMÉ: L'objectif de ce travail est de fournir des subventions pour la formation à distance des enseignants dans les études supérieures, engagés dans la recherche, les avancées dans la production scientifique et la publication de leurs résultats. Le travail est structuré en trois parties: aperçu des politiques, règlements et structures d'éducation à distance dans l'enseignement supérieur au Brésil; principes de construction d'interaction, de réflexion, de recherche, de collaboration et de connaissances; des contributions pour la réalisation d'études supérieures à distance.

Mots-clés: L'enseignement à distance. Diplômes d'études supérieures. La recherche. La construction de la connaissance. L'environnement d'apprentissage virtuel.

\section{Introdução}

A educação a distância (EaD) em cursos de distintos níveis de ensino se encontra consolidada em diferentes partes do mundo, a exemplo de países como Canadá, Espanha, Estados Unidos, Portugal e Reino Unido. No Brasil essa modalidade educacional se manteve muito tempo restrita a cursos profissionalizantes e supletivos, baseados na distribuição de materiais impressos para estudo e realização de tarefas pelos alunos. Posteriormente, os materiais impressos associados com as tecnologias de comunicação de massa impulsionaram o atendimento a contingente superior de alunos, porém atribuíram à EaD a reputação de educação de baixo custo e segunda classe. Somente após a Lei de Diretrizes e Bases da Educação (LDB) de 1996 é que a EaD tornou-se uma modalidade de educação regular possível de ser oferecida a distintos níveis de ensino e áreas de conhecimento com um sistema de regulação específico.

Este trabalho tem o objetivo de discutir as potencialidades e limitações de cursos de pós-graduação a distância em uma análise nas dimensões das políticas públicas, dos fundamentos e resultados de investigações científicas, buscando fornecer subsídios para o desenvolvimento de programas que possam ter como princípios básicos a investigação e a produção do conhecimento. Nesse sentido, o texto está estruturado em três partes, a saber: a) pesquisa documental sobre a visão geral das políticas, legislação, regulamentação e estrutura da EaD no ensino superior brasileiro e na pós-graduação stricto sensu; b) estudo na literatura sobre fundamentos teóricos e pesquisas empíricas relacionadas com a EaD no ensino superior e na pós-graduação stricto sensu; (c) metarreflexão sobre os "achados" na análise documental e no estudo da literatura a partir do qual emergem dez referências que podem contribuir para a 
realização de cursos de pós-graduação a distância ou na modalidade híbrida, voltados para a investigação e produção do conhecimento.

\section{A educação a distância como alternativa da formação}

A promulgação da LDB (Lei n. 9.394, de 20 de dezembro de 1996, especialmente os artigos 80 e 87) e leis complementares oficializaram a EaD como alternativa de formação regular para distintos níveis e áreas de conhecimento, tornando a educação superior mais acessível para pessoas residentes em áreas isoladas ou que não tiveram condições de cursá-la por diferentes motivos.

O Decreto n. 2.494, de 10 de fevereiro de 1998, regulamentou o disposto no artigo 80 da LDB e levou a EaD a ser tratada como "educação a distância", abandonando a característica de ensino supletivo emergencial, e reconheceu as especificidades da EaD como "uma forma de ensino que possibilita a autoaprendizagem, com a mediação de recursos didáticos sistematicamente organizados, apresentados em diferentes suportes de informação utilizados isoladamente ou combinados, e veiculados pelos diversos meios de comunicação" (art. 1ํㅡ). Ao mesmo tempo em que o Decreto avança ao trazer a expressão "educação a distância", ele anuncia uma ambiguidade no reconhecimento da EaD como modalidade de ensino (Demo, 1998), coloca o foco na autoaprendizagem, indica o uso das tecnologias como suporte à informação, esclarece (art. $2^{\circ}, \S 1^{\circ}$ ) que os programas de mestrado e de doutorado a distância terão regulamentação específica $e$ define as condições para a oferta da EaD por instituições públicas ou privadas, a partir de credenciamento específico, cujas normas foram especificadas pela Portaria n. 301, de 7 de abril de 1998, do Ministério da Educação (MEC).

Os cursos e as instituições são os sujeitos do ato educativo evidenciados no Decreto n. 2.494/98 e há uma omissão em relação ao trabalho do professor, que trouxe questões complexas relacionadas ao exercício desse profissional (Abreu-Tardelli, 2006), as quais podem ter influenciado práticas que perduram mesmo após a revogação desse Decreto e a promulgação dos decretos subsequentes. Isto se evidencia, por exemplo, no estudo de Almeida et al. (2012) sobre o curso de Pedagogia a distância, que revela distintas denominações e papéis atribuídos ao professor, assim como a precária condição do trabalho do tutor e a necessidade premente de se investir na consolidação do exercício da docência na EaD, no que diz respeito ao espaço e tempo de trabalho e à infraestrutura tecnológica para que ele tenha acesso ao curso e possa realizar seu trabalho.

O Decreto n. 5.622, de 19 de dezembro de 2005, indica uma evolução sobre a compreensão da $\mathrm{EaD}$ como um fenômeno do âmbito educativo, guardadas as especificidades da modalidade a distância, sendo, portanto, essencial a participação do professor e do aluno no ato pedagógico. 
Caracteriza-se a EaD como modalidade educacional na qual a mediação didático-pedagógica nos processos de ensino e aprendizagem ocorre com a utilização de meios e tecnologias de informação e comunicação, com estudantes e professores desenvolvendo atividades educativas em lugares ou tempos diversos. (Brasil, 2005)

Essa concepção de EaD normatiza a oferta de cursos superiores a distância e delineia um modelo que se desenvolve por meio de polos de apoio presencial, cuja legislação posterior esclarece a opção adotada pelo governo brasileiro. Nesse sentido, o Decreto n. 5.773, de 9 de maio de 2006, estabeleceu as funções de regulação, supervisão e avaliação dos cursos a distância, cujos procedimentos constam da Portaria Normativa n. 2/2007(revogada), com a finalidade de controlar e ordenar a expansão dos polos de apoio presencial das respectivas instituições.

O Decreto n. 6.303, de 12 de dezembro de 2007, vigente até o presente (agosto de 2012), altera dispositivos dos Decretos n. 5.622/05 e 5.773/06, detalha as funções de regulação, supervisão e avaliação de instituições de educação superior (presencial e a distância), ${ }^{1}$ de cursos de graduação e sequenciais. Desse modo, a nova redação do artigo 10 do Decreto n. 5.622/05, dada pelo Decreto n. 6.303/07, explicita o modelo de EaD adotado pelo governo brasileiro no que se refere à oferta por meio de polos de apoio presencial, devidamente credenciados in loco, com a finalidade de viabilizar as atividades presenciais obrigatórias, entre as quais avaliação, estágios, defesa de trabalhos e práticas laboratoriais. O Decreto esclarece também um aspecto não tratado na legislação anterior relacionado às instituições estaduais de educação superior, que passam a se submeter aos critérios prévios de credenciamento do sistema federal, quando pretenderem oferecer cursos superiores a distância.

No que tange à pós-graduação stricto sensu, os Decretos n. 5.622/05 e 6.303/07 remetem à Coordenação de Aperfeiçoamento de Pessoal de Nível Superior (Capes) a responsabilidade da normatização.

A associação entre leis, decretos e portarias com as políticas do MEC criou um arcabouço jurídico-legal para sustentar a implantação da EaD, caracterizada por um modelo baseado na oferta de cursos por meio de polos de apoio presencial e tutoria para atendimento ao aluno, estimulou o uso das tecnologias e definiu seu funcionamento nas mesmas instituições que realizam o ensino presencial, porém em um sistema paralelo, com exigência específica de credenciamento e autorização para os cursos a distância.

Esse acelerado crescimento se sustenta em princípios da industrialização (Peters, 2004) com base na educação de massa, no aumento da escala de atendimento e na replicação de cursos, encontrando-se em consonância com a literatura internacional dos anos de 1980 e início dos de 1990, quando a ênfase da EaD incidia sobre a distribuição de material instrucional e o planejamento das estratégias de ensino (Keegan, 1983). 
A exigência da LDB (artigo 62) de formação em nível superior, como condição para o docente ingressar na educação básica, levou à adoção da EaD para a oferta de cursos de licenciatura por meio da criação de associações entre instituições de ensino superior e redes públicas de ensino, viabilizando tal formação aos docentes em exercício em polos de apoio presencial implantados sob responsabilidade dessas redes. Assim, no ano 2000, surgiu a primeira rede de instituições privadas, denominada Universidade Virtual Brasileira (UVB), e o primeiro consórcio entre instituições de ensino superior (IES) públicas do Brasil: Consórcio de Universidades Públicas do Rio de Janeiro (Cederj).

Em junho de 2004, o MEC lançou uma Chamada Pública n. 1/2004 para financiar cursos de licenciatura a distância nas áreas de Pedagogia, Física, Química, Matemática e Biologia, denominada Pró-Licenciatura, específica para as universidades públicas organizadas em consórcios, que deveriam propor um único projeto para implementação em todas as instituições parceiras (Carvalho \& Pimenta, 2010).

O Decreto n. 5.800, de 8 de junho de 2006, oficializou a criação do Sistema Universidade Aberta do Brasil (UAB), como uma "parceria entre consórcios públicos nos três níveis governamentais (federal, estadual e municipal)" (Brasil, 2006b, s/p), ancorado, sobretudo, nas Instituições Federais de Ensino Superior (Ifes). Para induzir a oferta, a Portaria n. 873 - de 7 de abril de 2006 -, do MEC, autorizou, em caráter experimental por dois anos, todas as IES públicas que protocolizaram pedidos de credenciamento ${ }^{2}$ a implantarem os cursos solicitados. Em 2009, o Pró-Licenciatura foi incorporado à $\mathrm{UAB}$, cuja gestão nacional foi transferida para a Capes, a quem cabe, desde o ano de 2010, a operacionalização do Sistema, conforme Portaria n. 318, de 2 de abril de 2009.

A implantação da $\mathrm{EaD}$ no ensino superior brasileiro propiciou expandir sua abrangência. Porém, as demandas se sobrepõem à capacidade de resposta das universidades (Clark, 1998) e impõem uma acelerada e intempestiva oferta, o que dificulta a implantação de adequada infraestrutura e a preparação de docentes condizentes com uma atuação em espaços de ensino e aprendizagem midiatizados pelas TDIC e por outros recursos, o que tende a comprometer a qualidade e a reproduzir ou até potencializar as precárias condições do ensino presencial (Pretto \& Picanço, 2005).

Se, de um lado, a UAB induziu a oferta da formação de professores pelas universidades públicas, de outro, criou um programa implantado em universidades convencionais com práticas presenciais, demandando equipes com competências teóricas e práticas nem sempre disponíveis, uma vez que não se trata de apenas transpor conteúdos de cursos presenciais para materiais didáticos impressos ou digitais ou mesmo para videoaulas. $\mathrm{O}$ ato educativo se concretiza na interação social entre alunos e professores e, no caso da EaD, este ato se concretiza na midiatização 
de tecnologias. Há assim uma contradição entre as possibilidades de abrangência e expansão da EaD e a qualidade da educação, o potencial propiciado pelo uso das TDIC e as reais condições de acesso a essas tecnologias, a estrutura do sistema público de ensino e as novas demandas e desafios impostos pela evolução da ciência e da sociedade (Moraes, 2010).

A melhoria da educação básica evidencia a relevância de atuar simultaneamente na universalização da formação em nível superior e elevar o nível de formação de educadores para além da graduação. As políticas públicas para expansão da oferta de cursos de mestrado a distância trazem dilemas e tensões para educadores, pesquisadores e instituições, que assumem posições extremas entre o ufanismo com mostras de entusiasmo ingênuo e a descrença resistente, negando a priori o debate com vistas a aprofundar a compreensão sobre os limites e potencialidades da EaD. É inevitável admitir que a modalidade a distância ou híbrida (parte presencial e parte a distância) pode ser uma alternativa, em determinadas condições e circunstâncias, para a melhoria da educação brasileira, mas não se trata de abraçá-la como a solução para todos os problemas educacionais. É necessário reconhecer os avanços, dificuldades e equívocos já evidenciados no ensino superior a distância, a fim de identificar as possibilidades e os riscos para a EaD na pós-graduação.

A disseminação da EaD nas instituições de ensino superior impulsionou esforços de investigação em busca de alternativas para esta modalidade que explorem as características e funcionalidades das TDIC, tendo em vista o atendimento privilegiado dos estudantes segundo suas condições de aprendizagem, as características de seu contexto, as possibilidades de interação multidirecional e multimodal propiciadas por essas tecnologias, apoiando-se em referências teóricas e metodologias baseadas em princípios construcionistas, contextualizados, dialógicos e reflexivos, conforme evidenciado por Jonassen (1996), Duffy e Cunningham (1996), Valente, Prado e Almeida (2005).

O desenvolvimento de cursos de pós-graduação stricto sensu a distância, com a qualidade já alcançada no Brasil nos cursos de mestrado e doutorado na educação presencial, se relaciona com a preservação dos princípios da interação, colaboração, investigação, reflexão e construção do conhecimento, essenciais em qualquer modalidade educativa.

\section{Os princípios da interação, reflexão, investigação, colaboração e cons- trução do conhecimento na EaD evidenciados em estudo documental}

Nas últimas décadas, especialmente após a promulgação da LDB, a integração das TDIC na educação tornou-se prioridade das políticas educativas, evidenciando 
novos desafios às instituições formadoras e aos docentes que se dedicam à formação dos profissionais da educação.

O alcance dessas políticas se expressa no Anuário Brasileiro Estatístico de Educação Aberta e a Distância (Sanches, 2008), cujos dados mostraram pela primeira vez maior percentual $(33,6 \%)$ de uso preferencial de ambientes virtuais de aprendizagem (AVA) pelas instituições brasileiras, contra 30,7\% que afirmaram utilizar principalmente a mídia impressa, isolada ou articulada com outras mídias.

A tecnologia por si mesma, seja ela qual for, não garante a mudança de uma educação hierárquica, centralizada no papel do professor e na transmissão de informações, para uma educação participativa, democrática e solidária. Faz-se necessário um projeto político-pedagógico com intenção de criar espaço para a emancipação, a liberdade, a criação e a reflexão (Almeida, 2009) e que seja impulsionado pela incorporação e exploração das propriedades constitutivas das TDIC, com as distintas linguagens que estas veiculam, lógicas e formas específicas de comunicação articuladas com as "capacidades perceptivas, emocionais, cognitivas, intuitivas e comunicativas das pessoas" (Kenski, 2010, p. 22).

Diante disso, pode-se afirmar que é possível ressignificar a EaD com a midiatização das TDIC, com vistas a alterar o modo como essa modalidade educativa tem sido conduzida, apoiando-se em evidências de estudos nacionais e internacionais reconhecidos na literatura, que podem fornecer importantes referências para se delinear novas propostas de cursos de pós-graduação stricto sensu no Brasil que façam uso da EaD nas situações em se justifique tal opção, e não como uma oposição à educação presencial.

Jonassen (1996) desenvolveu um estudo com o propósito de reconceitualizar a EaD com o uso das TDIC, tendo em vista contribuir com a ressignificação do modo instrucionista como essa modalidade educativa vem sendo conduzida, reconceitualização esta buscada pelo foco deste artigo, que trata de cursos de pós-graduação stricto sensu voltados à investigação e produção de conhecimento. $\mathrm{O}$ autor propôs um conjunto de recomendações voltadas ao uso das TDIC para apoiar a aprendizagem construtivista na $\mathrm{EaD}$, com o uso de diversos recursos tecnológicos no desenvolvimento de processos de aprendizagem por meio de colaboração, exploração, experimentação, construção, conversação e reflexão.

As interações sociais e a colaboração na criação de significados compartilhados são amplamente apresentadas na literatura como relevantes para o compartilhamento de experiências e a produção de conhecimentos. Diversos autores estabelecem tais relações, entre eles Hargreaves (1998), Larraín e Hernández (2003), Fullan (2009) e Daniels (2003), e outros destacam a relevância da mediatização das TDIC nesses processos. 
Estudo realizado por Axt et al. (2006) sobre EaD em AVA, a partir de um experimento de processos coletivos de interação, identificou uma relação de interdependência entre os aspectos teórico-metodológicos e as tecnologias de suporte às atividades, configurando uma rede sustentada pelos conceitos de dialogismo, autoria e aprendizagem com distintos percursos individuais estabelecidos no coletivo. As autoras concluem que as tecnologias não têm sentido por si mesmas, mas dependem da metodologia das atividades, do mesmo modo que as propostas de trabalho precisam ser concebidas de acordo com as características das tecnologias.

Ao analisar a educação a distância na formação do educador reflexivo, Valente (2009) especifica a abordagem do estar junto virtual, segundo os princípios da interação, reflexão, investigação, colaboração e construção do conhecimento, colocando em evidência o potencial do trabalho com projetos para gerar novas teorias em um redemoinho de ideias, práticas, reflexões e produção de conhecimentos em diferentes contextos e situações educacionais.

Leite (2009) analisou a relação virtual estabelecida entre o orientador e seus orientandos em AVA, utilizado em curso de doutorado em uma universidade dos Estados Unidos da América. Por meio de depoimentos de alunos e outros participantes envolvidos no processo de produção a distância da tese, a autora discute a proposta pedagógica do curso a distância, que proporciona ao aluno a interação, a construção do conhecimento e a reflexão que viabilizam a produção científica do pesquisador em seu ambiente de trabalho.

Nessa perspectiva, a EaD que tem como suporte tecnológico as TDIC com o uso de AVA, associadas com as ferramentas e interfaces da web 2.0, potencializa desenvolver processos formativos baseados na comunicação multidirecional e multimodal, acesso instantâneo a informações atualizadas por mecanismos automáticos de busca, navegação não linear entre nós de informações representadas por meio de múltiplas mídias (som, imagem, texto, animação, vídeo, hipertexto), registros digitais de processos e produções recuperados a qualquer momento e de qualquer lugar (Almeida, 2010). Tais possibilidades viabilizam a formação a distância de profissionais que se encontram no exercício de seu ofício, ao mesmo tempo em que eles se mantêm parcialmente atuantes em seu local de trabalho, dando-lhes oportunidade para tomar a própria prática como objeto de investigação.

O currículo se reestrutura em uma arquitetura pedagógica (Carvalho, Nevado \& Menezes, 2007) que coloca os formandos como protagonistas orientados pelos professores, para que desenvolvam a autonomia na busca de informações em distintas fontes de referência advindas da bibliografia, da internet e da interação em comunidades virtuais, na reflexão e no questionamento contínuo, na organização da investigação, na coleta de dados, no registro sistemático e na formalização 
do conhecimento. Essa formação se desenvolve entrelaçada com a investigação, ampliando a concepção de currículo e os horizontes da pedagogia, incorpora didáticas abertas e flexíveis, redimensiona o espaço, o tempo, o contexto de aprendizagem, as formas de comunicação, propõe diferentes rotas para os formandos percorrerem de acordo com os problemas de investigação abraçados.

O currículo que se desenvolve em consonância com a formação e a investigação é concebido como construção social (Goodson, 2001) estabelecida na interação dialógica, integrando o conhecimento científico com as concepções, valores, crenças, experiências, tecnologias e estratégias, em processos de atribuição de novos significados e negociação de sentidos, produzindo percursos diversificados (Almeida \& Valente, 2011).

Os estudos apresentados evidenciam que o uso das TDIC potencializa a EaD com base em fundamentos teóricos relacionados ao "pensamento reflexivo, conversacional, contextual, complexo, intencional, colaborativo, construtivo e ativo dos estudantes a distância" (Jonassen, 1996, p. 73), os quais são essenciais para a formação de pesquisadores em cursos de pós-graduação.

A próxima seção aborda uma metarreflexão sobre os "achados" na análise documental e no estudo da literatura, a partir dos quais emergem dez referências que se constituem como contribuições para a proposição de novos cursos de pós-graduação a distância, ou na modalidade híbrida, comprometidos com a investigação e a produção do conhecimento.

\section{A educação a distância na formação de educadores em cursos de pós-graduação stricto sensu}

As experiências de $\mathrm{EaD}$ em cursos de pós-graduação comprometidos com a pesquisa acadêmica é escassa na realidade brasileira, pois embora o Decreto n. 2.494 - que regulamenta o disposto no artigo 80 da LDB - faça referência aos programas de mestrado e doutorado a distância, estes teriam regulamentação específica (art. 2o , $\S 1^{\circ}$ ), ficando para definição posterior. Na legislação vigente, os Decretos n. 5.622/05 e 6.303/07 especificam que cabe à Capes editar normas complementares para regulamentar essa modalidade na pós-graduação stricto sensu. Contudo, não se encontram disponíveis informações sobre a regulamentação, critérios e condições para a oferta desses cursos a distância.

Na ausência de critérios específicos, é possível expandir a normatização dos cursos de graduação associados com os critérios de avaliação da Capes para a pósgraduação stricto sensu. Nesse sentido, pode-se supor que nessa expansão se encontram as bases do Programa de Mestrado Profissional stricto sensu em Matemática 
da Rede Nacional (Profmat) (Capes, 2010), lançado no final de 2010 pelo Sistema $\mathrm{UAB}$, implantado por uma associação de instituições públicas de ensino superior do Brasil, que juntas ofereceram 1.192 vagas em 54 polos de atendimento de um curso semipresencial. O Regimento desse Programa explicita a intenção de manter o rigor metodológico com base nos fundamentos científicos das instituições parceiras, com uma seleção de docentes a partir das exigências de grau mínimo de mestre, formação e experiência em ensino de Matemática (Regimento do Profmat, capítulo VI, artigo $\left.29^{\circ}\right)$.

Este Regimento mostra uma questão conflituosa no que tange à manutenção do rigor metodológico com base nos fundamentos científicos, uma vez que o curso se apoia em orientadores detentores do grau mínimo de mestre, ao passo que no mestrado acadêmico, cujo formando recebe um título com os mesmos direitos, necessariamente tem um orientador com grau mínimo de doutor. Cabe então questionar sobre os riscos que se corre de adentrar pelos mesmos problemas e contradições enfrentados pela EaD nos cursos de graduação, conforme apontado na primeira parte deste texto (Clark, 1998; Pretto \& Picanço, 2005; Moraes, 2010; Almeida et al., 2012) com a alta escala da oferta da EaD sem os cuidados com a adequada infraestrutura e preparação de docentes, agravada agora pelas exigências da produção científica e da inovação.

A Portaria Normativa n. 17, do MEC, de 28 de dezembro de 2009 (Brasil, 2009), preconiza que o mestrado profissional propicia a formação para a prática em atividades técnico-científicas e de inovação por meio do método científico, da pesquisa aplicada e da busca de solução para problemas específicos. Considera-se que formação para a prática significa formação na prática que se desenvolve na relação com a teoria, constituindo-se a práxis (Sanchez Vazquez, 2007) e não uma prática centrada no fazer dicotomizado do compreender. Trata-se, portanto, de uma formação complexa, que exige professores bem preparados e experientes, que possam dar conta da tarefa de orientar os demais professores para que possam investigar e teorizar sobre a própria prática, em busca de encontrar solução para os problemas de sua realidade de trabalho e de seu alunado.

Se, no Brasil, essa iniciativa de mestrado profissional semipresencial tem sido considerada pioneira, em outros países a EaD é uma modalidade usual no mestrado e no doutorado de diferentes áreas de conhecimento. Alguns exemplos reconhecidos internacionalmente são realizados por diversas universidades, tais como: University of Phoenix (http://www.phoenix.edu/), dos Estados Unidos da América; Athabasca University (http://www.athabascau.ca/), do Canadá; Open University (http://www.open.ac.uk/), do Reino Unido; Universidade Aberta de Portugal (http://www.uab.pt); Universidad Nacional de Educación (http://portal.uned.es/), da Espanha. Essas universidades apresentam uma característica comum no que se refere a uma atuação voltada à educação a distância ou híbrida, ou seja, elas se 
originam de projetos destinados a uma modalidade específica em distintos níveis de ensino e na educação aberta, o que impulsionou a rápida implementação de seus projetos, devido à ausência de conflitos pela oposição entre educação presencial e a distância.

De modo diferente, o modelo de EaD adotado no Brasil não é de uma universidade, mas sim de uma modalidade de ensino que surge em universidades convencionais, que assumiram a modalidade a distância com os profissionais disponíveis, o que gerou desafios, dilemas e ambiguidades. Porém, à medida que os docentes brasileiros enveredam por essa nova forma de exercer sua profissão, eles começam a enfrentar um dos desafios contemporâneos relacionados com a incorporação de tecnologias aos processos de ensinar, aprender e pesquisar, sob múltiplos enfoques (Mill \& Pimentel, 2010).

As universidades internacionais citadas desenvolvem investigações sobre EaD, e-learning, aprendizagem midiatizada pelas TDIC e temas relacionados. No Brasil, as pesquisas nesse campo são escassas (idem, ibid.) e, quando existem, os temas mais frequentes tratam da formação de professores a distância no ensino superior, com poucos trabalhos sobre os cursos de pós-graduação stricto sensu.

Masetto et al. (2005) desenvolveram pesquisa-ação sobre uma disciplina do Programa de Pós-Graduação em Educação: Currículo, da Pontifícia Universidade Católica de São Paulo (PUC-SP), realizada a distância por meio da plataforma Teleduc. A pesquisa identificou intensa participação dos alunos, que pode ter sido influenciada pela abordagem teórico-metodológica fundada no diálogo e na investigação, com o levantamento inicial dos temas de interesse dos alunos relacionados à formação de educadores a distância, objeto de estudos em grupos colaborativos que desenvolveram produções com acompanhamento e orientação, na perspectiva do "estar junto virtual" (Valente, 2009). Uma das dificuldades referidas foi a intensa carga horária de dedicação dos envolvidos, demandando empenho e esforço superiores ao exigido em uma disciplina presencial e indicando a necessidade de rever as horas de dedicação docente na EaD (Abreu-Tardelli, 2006).

Investigação desenvolvida por Assis (2011) sobre os desafios encontrados por professores de universidades na integração das TDIC às suas práticas pedagógicas, por meio de estudo exploratório no Reino Unido e pesquisa empírica no Brasil, aponta como resultado que os professores pesquisados planejam de modo empírico, assistemático e com pouco uso das TDIC. Nesse sentido, Laurillard (2007, p. 15) identifica que o uso das TDIC pelos educadores tem ocorrido de modo conservador, deixando de explorar as reais possibilidades das tecnologias para a educação.

Os resultados evidenciados por Abreu-Tardelli, Assis e Laurillard indicam a necessidade de rever questões sobre os aspectos trabalhistas, as condições institucionais 
e a preparação do professor para que ele possa compreender as propriedades das TDIC e desenvolver competências pedagógicas de uso dessas tecnologias, o que não se limita ao domínio instrumental e engloba a compreensão das concepções e potencialidades da integração das TDIC com o currículo, a proficiência pedagógica em sua utilização e as contribuições dessas tecnologias para a pesquisa.

Scherer (2005) propõe para os programas de pós-graduação o desenvolvimento de uma educação bimodal, com a integração de espaços presenciais e virtuais em um processo híbrido de aprendizagem e investigação, que propicie a reconciliação de elementos aparentemente disjuntos, como digital e analógico, interior e exterior, proximidade e distância, forma e conteúdo, teoria e prática, formação e investigação, preservando a identidade de tais elementos (Almeida, 2003).

Pesquisa realizada pelo Departamento de Educação dos Estados Unidos da América (Means et al., 2010), no período de 1996 a 2008, levantou na literatura milhares de estudos empíricos sobre a aprendizagem online (midiatizada pelas TDIC) em distintos níveis de ensino. Por meio de triagem analítica, foram selecionados cinquenta estudos e submetidos à meta-análise, a fim de identificar os impactos que contrastaram ensino online e presencial. São resultados e recomendações relevantes para o presente trabalho:

- Os resultados dos estudantes foram maiores nas situações de aprendizagem que combinaram elementos online e presenciais em relação às atividades inteiramente presenciais ou puramente online, mas os pesquisadores sugerem que os efeitos positivos associados aos processos híbridos não devem ser atribuídos aos meios de comunicação por si só;

- Os maiores impactos foram identificados nas situações em que as aulas online envolviam a colaboração ou a orientação do professor mais do que naquelas em que os alunos trabalharam independente e individualmente;

- A aprendizagem foi aprimorada, ao atribuir aos alunos o controle das interações e ao impulsionar a reflexão;

- Os estudos em que havia a equivalência do currículo e do ensino entre as situações online e presencial tiveram impactos menores na aprendizagem do que os estudos nos quais havia mudanças no currículo e no ensino em relação às dinâmicas, organização das atividades e uso de recursos instrucionais;

- O uso de recursos como vídeo ou testes online não influenciou a aprendizagem online, assim como a inserção de mais recursos midiáticos em atividade online não evidenciou melhorias; 
- A orientação para grupos de estudantes não se mostrou tão bem sucedida quanto para cada aluno individualmente. Quando grupos de alunos trabalharam online, em conjunto, o apoio de mecanismos como, por exemplo, colocar questões norteadoras impulsionou a interação, mas não influenciou a aprendizagem.

Assim, o estudo de Means et al. (op. cit.) converge com a concepção aqui defendida de uma educação a distância na pós-graduação que associa momentos presenciais e online, em que as condições de espaço e tempo sejam definidas conforme as características do curso e, sobretudo, conte com a efetiva participação de professores e alunos que fazem uso das TDIC para o diálogo, a colaboração, a investigação, a reflexão, o registro de processos e de produção de conhecimento.

Os "achados" evidenciados na análise documental e os resultados destacados no estudo da literatura, associados às possibilidades abertas pelas políticas atuais de formação de educadores na pós-graduação stricto sensu, permitem elencar um conjunto de referências que podem contribuir para a elaboração de propostas de novos cursos comprometidos com a investigação e a produção de conhecimento, a saber:

1. Compromisso com o desenvolvimento de métodos científicos com o rigor metodológico inerente a processos de investigação e produção de conhecimento, o que exige a implantação de adequada infraestrutura e projetos pedagógicos coerentes com os princípios da interação, reflexão, colaboração e construção do conhecimento.

2. Adoção de uma concepção de avaliação, critérios e procedimentos em consonância com esses fundamentos, mantendo a coerência teórica e metodológica entre a avaliação dos projetos pedagógicos dos cursos e a aprendizagem dos estudantes.

3. Construção de novos projetos de formação de educadores em pós-graduação que aproximem e integrem a dimensão formativa com as situações de trabalho, explorando as possibilidades da educação midiatizada pelas TDIC que oportunizam ao profissional participar da formação e permanecer em seu local de trabalho, fazendo deste seu objeto de estudos, em busca de solução para os problemas concretos e de geração de processos de inovação apropriados para seu contexto.

4. Desenvolvimento da formação na modalidade bimodal, com a integração de espaços presenciais e virtuais em um processo híbrido de aprendizagem e investigação, com flexibilidade de tempo e espaço de aprendizagem. 
5. Relevância do papel do docente na educação midiatizada pelas TDIC, ao promover o diálogo com o aluno, orientar sua trajetória de aprendizagem, fomentar a colaboração e a produção científica; dessa forma, o docente torna-se também um aprendiz sobre os modos de aprender dos estudantes e respectivas estratégias de construção de conhecimentos representados por meio de múltiplas linguagens, assim como sobre os novos conhecimentos advindos das investigações em desenvolvimento.

6. Preparação de docentes de programas de pós-graduação para que desenvolvam as competências pedagógicas de uso das TDIC na midiatização da formação de educadores presencial, a distância ou híbrida, por meio da integração entre as dimensões: teórica, relacionada com sua área de conhecimento e atuação; pedagógica, com as estratégias de mediação, comunicação, orientação e acompanhamento do aluno e respectivos processos de aprendizagem; e tecnológica, com o domínio das tecnologias e as competências pedagógicas de integração das TDIC ao currículo e à pesquisa científica.

7. Definição de políticas consistentes voltadas à constituição de uma sociedade de aprendizagem ao longo da vida e à criação de condições institucionais adequadas para que os docentes tenham disponibilidade de tempo para exercer sua profissão com o uso das TDIC, interagir com os demais profissionais que atuam nas equipes de EaD, estudar, preparar atividades pedagógicas condizentes com as características dos alunos, os conceitos em estudo e as tecnologias em uso.

8. Fomento ao desenvolvimento de investigação sobre a formação de educadores a distância que combine situações de formação presencial e a distância, em programas de pós-graduação no Brasil e no exterior.

9. Reconhecimento das características dos estudantes, seus interesses, questionamentos, necessidades de aprendizagem e contexto, conhecimentos prévios sobre os temas de estudo, condições de acesso e estágio de apropriação das tecnologias. Da mesma forma, identificação das características, preferências e dificuldades dos docentes e modos de conduzir as práticas pedagógicas e orientar os trabalhos de seus alunos.

10. Criação de estratégias de aprendizagem com suporte nas TDIC que propiciem aos alunos a autonomia para interagir com colegas e professores, a integração de mídias e tecnologias em suas produções e a reflexão sobre a própria aprendizagem e desenvolvimento.

Esse conjunto de referências pode ser a base inicial em torno da qual se organizam programas de pós-graduação a distância stricto sensu, fundamentados em 
concepções teórico-metodológicas coerentes com as características dos problemas em estudo e que possam explorar as potencialidades das TDIC para desenhar trajetórias de investigação específicas, compreendendo que a educação é apenas uma, independente da modalidade. Afinal, na pós-graduação, com maior ou menor intensidade, os docentes já realizam as atividades de orientação a distância com o uso de diferentes meios tecnológicos.

\section{Considerações finais}

Este estudo buscou trazer subsídios para a formação de educadores em cursos de pós-graduação stricto sensu, a distância ou na modalidade híbrida, que se encontra intrinsecamente imbricada com a produção de novos conhecimentos e com a inovação educativa, trazendo da literatura evidências de que esses processos se realizam por meio dos princípios da interação, colaboração, investigação, reflexão e construção do conhecimento. O uso de ambientes virtuais de aprendizagem com suporte nas TDIC potencializa concretizar essa formação, uma vez que permite romper com as barreiras espaço-temporais, registrar processos e desenvolver produtos identificados pelos registros digitais, integrar currículo e tecnologias, viabilizar narrativas curriculares e desenvolver trajetórias metodológicas singulares nas investigações.

O resgate da literatura associado à análise de estudos sobre experiências de EaD propiciou a compreensão sobre as condições apropriadas à formação de educadores a distância na pós-graduação - comprometida com a investigação, a produção de conhecimento e a inovação - e viabilizou a realização de uma metarreflexão, a partir da qual emergiram dez referências que se constituem como contribuições para a implantação de cursos de pós-graduação com a midiatização de tecnologias, combinando atividades presenciais a distância.

Outra contribuição deste estudo se refere à compreensão de que as modalidades de educação a distância e educação presencial não se opõem, mas se complementam e se imbricam por meio do potencial das TDIC, que possibilitam a integração de ações em contextos distintos. Cria-se, assim, uma rede entre o ambiente de aprendizagem, o cotidiano e o espaço de trabalho, configurando novos caminhos para a compreensão da educação e da cultura e para o desenvolvimento científico, social, pessoal e profissional.

\section{Notas}

1. A Portaria Normativa n 40, de 12 de dezembro de 2007, do ministro de Estado da Educação, instituiu o sistema e-MEC, que faz atualmente todo o controle de fluxo e gestão de informações do processo de regulação, supervisão e avaliação do ensino superior brasileiro. 
2. A Portaria n. 1.368, de 7 de dezembro de 2010, renovou o credenciamento das instituições públicas de ensino superior (Ipes) vinculadas ao Sistema UAB para a oferta de cursos superiores na modalidade a distância, pelo prazo de 5 (cinco) anos.

\section{Referências}

ABREU-TARDELLI, L.S. trabalhodoprofessor@chateducacional.com.br: aportes para compreender o trabalho do professor iniciante em EaD. 2006. Tese (Doutorado em Linguística Aplicada e Estudos da Linguagem) - Pontifícia Universidade Católica de São Paulo, São Paulo.

ALMEIDA, F.J. Paulo Freire. São Paulo: Publifolha, 2009.

ALMEIDA, M.E.B. Educação a distância na internet: abordagens e contribuições dos ambientes digitais de aprendizagem. Educação \& Pesquisa, São Paulo, v. 29, n. 2, p. 327-339, 2003.

ALMEIDA, M.E.B. Currículo, avaliação e acompanhamento na educação a distância. In: MILL, D.; PIMENTEL, N. Escritos sobre educação a distância: desafios contemporâneos sob múltiplos enfoques. São Carlos: Edufscar, 2010.

ALMEIDA, M.E.B.; VALENTE, J.A. Tecnologias e currículo: trajetórias convergentes ou divergentes? São Paulo: Paulus, 2011.

ALMEIDA, M.E.B. et al. Educação a distância: oferta, características e tendências dos cursos de licenciatura em Pedagogia. In: ESTUDOS e pesquisas educacionais. São Paulo: Fundação Victor Civita, 2012. (Relatório final). Disponível em: <http://www. fvc.org.br/estudos-e-pesquisas/2011/relatoriofinal.pdf>. Acesso em: 2 set. 2012

ASSIS, M.P. Learning design: conceitos, métodos e ferramentas. 2011. Tese (Doutorado em Educação) - Programa de Pós-Graduação em Educação, Pontifícia Universidade Católica de São Paulo, São Paulo.

AXT, M. et al. Interação dialógica: uma proposta teórico-metodológica em ambientes virtuais de aprendizagem. Novas Tecnologias na Educação, Porto Alegre, v. 4, n. 1, jul. 2006. Disponível em: <http://seer.ufrgs.br/renote/article/view/14041/7929>. Acesso em: 27 maio 2011.

BRASIL. Decreto n. 2.494, de 10 de fevereiro de 1998. Regulamenta o Art. 80 da LDB (Lei n.o 9.394/96). Diário Oficial da União, Brasília, DF, 11 fev. 1998.

BRASIL. Decreto n. 5.622, de 19 de dezembro de 2005. Regulamenta o art. 80 da Lei no 9.394, de 20 de dezembro de 1996, que estabelece as diretrizes e bases da educação nacional. Diário Oficial da União, Brasília, DF, 20 dez. 2005. 
BRASIL. Decreto n. 5.773, de 9 de maio de 2006. Dispõe sobre o exercício das funções de regulação, supervisão e avaliação de instituições de educação superior e cursos superiores de graduação e seqüenciais no sistema federal de ensino. Diário Oficial da União, Brasília, DF, 10 maio 2006a.

BRASIL. Decreto n. 5.800, de 8 de junho de 2006. Dispõe sobre o Sistema Universidade Aberta do Brasil - UAB. Diário Oficial da União, Brasília, DF, 9 jun. 2006b.

BRASIL. Decreto n. 6.303, de 12 de dezembro de 2007. Altera dispositivos dos Decretos nos 5.622, de 19 de dezembro de 2005, que estabelece as diretrizes e bases da educação nacional, e 5.773, de 9 de maio de 2006, que dispõe sobre o exercício das funções de regulação, supervisão e avaliação de instituições de educação superior e cursos superiores de graduação e seqüenciais no sistema federal de ensino. Diário Oficial da União, DF, 13 dez 2007.

BRASIL. Decreto n. 6.755, de 29 de janeiro de 2009. Institui a Política Nacional de Formação de Profissionais do Magistério da Educação Básica, disciplina a atuação da Coordenação de Aperfeiçoamento de Pessoal de Nível Superior - CAPES no fomento a programas de formação inicial e continuada, e dá outras providências. Diário Oficial da União, Brasília, DF, 30 jan 2009.

BRASIL. Lei n. 9.394, de 20 de dezembro de 1996. Estabelece as diretrizes e bases da educação nacional. Diário Oficial da União, Brasília, DF, 23 dez. 1996.

BRASIL. Ministério da Educação. Portaria Ministerial n. 301, de 7 de abril de 1998. Diário Oficial da União, Brasília, DF, 9 abr. 1998.

BRASIL. Ministério da Educação. Portaria Ministerial n 318, de 2 de abril de 2009. Diário Oficial da União, Brasília, DF, 2009.

BRASIL. Ministério da Educação. Portaria Ministerial n. 873, de 7 de abril de 2006. Diário Oficial da União, Brasília, DF, 11 abr. 2006.

BRASIL. Ministério da Educação. Portaria Ministerial n. 1.368, de 7 de dezembro de 2010. Diário Oficial da União, Brasília, DF, 8 dez. 2010.

BRASIL. Ministério da Educação. Portaria Normativa n. 2, de 10 de janeiro de 2007. Diário Oficial da União, Brasília, DF, 11 jan. 2007.

BRASIL. Ministério da Educação. Portaria Normativa n. 17, de 28 de dezembro de 2009. Diário Oficial da União, Brasília, DF, 29 dez. 2009. Seção 1, p. 20.

CARVALHO, A.B.G.; PIMENTA, S.A. Políticas públicas de formação de professores da educação básica a distância: o contexto do Pró-Licenciatura. Práxis Educacional, Vitória da Conquista, v. 6, n. 9, p. 101-123, jul./dez. 2010. 
CARVALHO, M.J.S.; NEVADO, R.A.; MENEZES, C.S. Arquiteturas pedagógicas para educação a distância. In: NEVADO, R.A.; CARVALHO, M.J.S.; MENEZES, C.S. (Org.). Aprendizagem em rede na educação a distância: estudos e recursos para formação de professores. Porto Alegre: Ricardo Lenz, 2007.

CLARK, B. Creating entrepreneurial universities: organizational pathways of transformation. London: Pergamon, 1998.

COORDENADORIA DE APERFEIÇOAMENTO DE PESSOAL DE NIVEL SUPERIOR (CAPES). Programa de Mestrado Profissional em Matemática em Rede Nacional (PROFMAT). Brasília, DF: MEC/Capes, 2010.

DANIELS, H. Vygotsky e a pedagogia. Trad. Milton Camargo Mota. São Paulo: Loyola, 2003.

DEMO, P. Questões para a Teleducação. Petrópolis: Vozes, 1998.

DUFFY, T.M., CUNNINGHAM, D. Constructivism: implications for the design and delivery of instruction. In: JONASSEN, D.H. (Ed.). The handbook of research on educational comunications and technology. New York: Macmillan, 1996. p. 170-198.

FULLAN, M. O significado da mudança educacional. 4. ed. Porto Alegre: Artmed, 2009.

GOODSON, I. O currículo em mudança: estudos na construção social do currículo. Porto: Porto, 2001.

HARGREAVES, A. Os professores em tempos de mudança. Lisboa: McGraw-Hill, 1998.

JONASSEN, D. O uso das novas tecnologias na educação a distância e a aprendizagem construtivista. Em Aberto, Brasília, DF, v. 16, n. 70, p. 70-88, abr./jun. 1996. Disponível em: <http://www.rbep.inep.gov.br/index.php/emaberto/article/view/1054/956>. Acesso em: 2 jun. 2011.

KEEGAN, D. Six distance education theorists. Hagen: Fern Universitat Hagen, 1983.

KENSKI, V. Tecnologias e ensino presencial e a distância. Campinas: Papirus, 2010.

LARRÍN, V.; HERNÁNDEZ, F. O desafio do trabalho multidisciplinar na construção de significados compartilhados. Pátio, Porto Alegre, v. 7, n. 26, p. 45-48, 2003.

LAURILLARD, D. Foreword. In: BEETHAM, H.; SHARPE, R. (Ed.). Rethinking pedagogy for a digital age: designing and delivering e-learning. London: Routledge, 2007. p. xv-xvii.

LEITE, L.S. Formando profissionais reflexivos na sala de aula do século XXI. In: VALENTE, J.A.; BUSTAMANTE, S.B.V. Educação a distância: prática e formação do professor reflexivo. São Paulo: Avercamp, 2009. p. 37-62. 
MASETTO, M.T. et al. Formação de professores em ambiente digital: uma experiência interdisciplinar. Informática na Educação: teoria e prática, Porto Alegre, v. 8, n. 2, jul./dez. 2005. Disponível em: <http://seer.ufrgs.br/InfEducTeoriaPratica/article/ view/8174/4860>. Acesso em: 22 maio 2011.

MEANS, B. et al. Evaluation of evidence-based practices in online learning: a meta-analysis and review of online learning studies. Washington, DC: U. S. Department of Education/Office of Planning, Evaluation and Policy Development Policy and Program Studies Service; Center for Technology in Learning, 2010. Disponível em: <http:// www2.ed.gov/rschstat/eval/tech/evidence-based-practices/finalreport.pdf $>$. Acesso em: 6 jun. 2011.

MILL, D.; PIMENTEL, N. Escritos sobre educação a distância: desafios contemporâneos sob múltiplos enfoques. São Carlos: Edufscar, 2010.

MORAES, R.A. Institucionalização da EaD nas IES públicas: uma perspectiva histórico-crítica e emancipadora. In: MILL, D.; PIMENTEL, N. Escritos sobre educação a distância: desafios contemporâneos sob múltiplos enfoques. São Carlos: Edufscar, 2010. p. 319-349.

PETERS, O. A educação a distância em transição: tendências e desafios. Trad. Leila Ferreira de Souza Mendes. São Leopoldo: Unisinos, 2004.

PRETTO, N.L.; PICANÇO, A.A. Reflexões sobre EaD: concepções de educação. In: ARAÚJO, B.; FREITAS, K.S. Educação a distância no contexto brasileiro: algumas experiências da UFBA. Salvador: ISP; UFBA, 2005. p. 31-56. Disponível em: <http:// www.proged.ufba.br/ead/EAD\%2031-56.pdf>. Acesso em: 25 abr. 2011.

SANCHEZ, F. (Coord.). Anuário Brasileiro Estatístico de Educação Aberta e a Distância. 4. ed. São Paulo: Instituto Monitor, 2008.

SANCHEZ VAZQUEZ, A. Filosofia da práxis. Buenos Aires: Clacso; São Paulo: Expressão Popular, 2007.

SCHERER, S. Uma estética possível para a educação bimodal: aprendizagem e comunicação em ambientes presenciais e virtuais. 2005. Tese (Doutorado em Educação) Programa de Pós-Graduação em Educação, Pontifícia Universidade Católica de São Paulo, São Paulo.

VALENTE, J.A. O "estar junto virtual” como uma abordagem de educação a distância: sua gênese e aplicações na formação de educadores reflexivos. In: VALENTE, J.A.; BUSTAMANTE, S.B.V. Educação a distância: prática e formação do professor reflexivo. São Paulo: Avercamp, 2009. p. 37-62. 
Formação de educadores a distância na pós-graduação...

VALENTE, J.A.; PRADO, M.E.B.B.; ALMEIDA, M.E.B. Educação a distância via internet. São Paulo: Avercamp, 2005.

Recebido em 6 de agosto de 2011.

Aprovado em 02 de agosto de 2012 